\title{
RETRACTION
}

\section{Synergistic interactions between MEK1/2 and histone deacetylase inhibitors in BCR/ABL+ human leukemia cells}

C Yu, G Dasmahapatra, P Dent and S Grant

Leukemia (2016) 30, 1452; doi:10.1038/leu.2016.7; published online 8 April 2016

Retraction to: Leukemia (2005) 19: 1579-1589. doi:10.1038/ sj.leu.2403868

Following notification by the corresponding author (S Grant), the Editors and Publisher wish to retract this paper due to improper preparation of figures, most notably in the duplication of tubulin and other loading controls in multiple figures.

S Grant and P Dent agreed to this retraction. C Yu and G Dasmahapatra could not be reached to comment on the retraction. 